\title{
Theoretical Frameworks and the Extended Curriculum Programme
}

\author{
James Garraway \\ Vivienne Bozalek
}

\section{Abstract}

Teaching and learning initiatives in foundation provision have the potential to more generally improve teaching practices across the university. The innovative practices are, however, not always underpinned by deeper theoretical understandings about how knowledge is structured, how pedagogies are enacted and how students learn new ideas. Such understandings matter as they support and strengthen the teaching initiatives. Theory, in some instances, enables practices to be lifted from their contexts so that they are more easily transferable to different subjects or levels, and, in other circumstances, to alert higher education teachers to the importance of including epistemology, ontology and ethics in their thinking. Furthermore, and importantly, theories help us to identify blindspots, dominant assumptions and common sense. There has recently been an upsurge in research into teaching and learning on foundation reported in the literature. The purpose of this article is, firstly, to present and synthesise more mainstream social realist theorisations of teaching and learning, as well as newer theoretical approaches which some articles in this special edition use, which are based on posthumanism, new materialism and non-representational theory, all of which are predicated on relational ontology and process philosophy.

Keywords: Foundation provision, extended curriculum programmes, theories, teaching and learning, curriculum 


\section{Introduction}

What are now known as 'foundation provision', (FP), or 'extended curriculum programmes' (ECPs) in South Africa arose primarily as a means to give black students access to university (Department of Higher Education 2012), mostly in the then historically white universities (HWUs) in the 1980s and 1990s (Dhunpath \& Vithal 2014). These programmes now exist in some form in 24 universities across South Africa, with a total budget of R336 Million for 2017/2018 (Ministerial Statement on University Funding 2017/ 2018).

In its current form FP was a direct response, not so much to addressing concerns of access to higher education (HE), but rather to the disturbingly high drop out and failure rates of students entering first year. In general, only about $35 \%$ of students who began their studies in early 2000 actually graduated five years later, putting great strain on the fiscus and the need for skilled graduates in a developing economy, but also having social impact on those whose dreams of success have been shattered (Scott, Yeld \& Hendry 2007). At that time the throughput rate was strongly racially skewed, with the ratio of white to African throughput standing at 2:1. Throughput statistics are notoriously difficult to ascertain however, more recent research (2009 - 2015) from the University of Stellenbosch (Broekhuizen, Van der Berg \& Hofmeyr 2016) indicates a similar trend, but alerts us to two additional trends. Firstly, throughput after 4 years is $36.9 \%$ but after 6 years $58 \%$ and, secondly, the ratio of white to African throughput is still racially skewed but less so than earlier, at 72\%:54\% respectfully.

FP or ECP thus focuses on students who meet the requirements for university, and gain access, but because of the initial educational and social disadvantage are less able to complete their studies than those students who have had access to schooling systems which prepare them more adequately for university (Department of Higher Education 2012).

FP is an attempted academic solution to student drop out (Scott 2014). It does this through providing students with an additional year of study, usually in the form of an extended year 1. The additional study time is expected to employ innovative and responsive teaching techniques to deliver an enriched and supportive curriculum that prepares students for their current and future studies. As such there is an expectation that teaching staff would be at the cutting edge of teaching in higher education. Yet FP teachers are often casualised through being on short to medium-term contracts and thus often do 
not attend otherwise compulsory new staff teaching induction courses or other staff development initiatives. Where staff are do attend such courses, rapid staff turnaround may result in loss of skill (McKenna 2014).

It is not surprising, therefore, that FP teaching and learning practices and curriculum development, despite their importance and complex nature, remain largely under-theorised, with teaching staff often relying on common sense approaches rather than those based on research (McKenna 2014; Boughey 2014).

There are thus two main issues with theorising foundation. There is firstly the overall lack of availability of theorisation of FP, and, where this has been attempted, it may be relatively superficial. For example, over half the papers in the SAJHE 2015 special foundation edition and most of the papers in Case Studies of Epistemological Access (Bozalek, Garraway \& McKenna 2011), two of the sources from which data is drawn in the first half of this paper, are descriptive, or in some instances reflective of cases or only partially theorised.

Secondly there is the issue of uptake of available research by teaching staff against the background of an often casualised staff contingent. This issue is not explored further in this article. But it is hoped that the formalisation of funding, such that it is part of the general university subsidy rather than in three-year cycles, will go some way to creating more permanent FP posts and so enable more systematic academic staff development.

The purpose of the article is then to seek better theorisation of foundation studies through examining critically theories which have been used to explicate pedagogy and scholarship in the field and also what is new on the horizon. Hopefully, this can enhance the teaching repertoires of lecturers and provide a more nuanced understanding of what students may contribute to teaching and learning, where opportunities for staff development are available and can be taken up,

From the outset, because of the focus on supporting disadvantaged students in their studies, FP has portrayed itself as a social justice project and has often been justified as such by staff who have fought for its continued existence and status as a necessary HE initiative over the years (Kloot, Case \& Marshall 2008). Social justice has had two variations in this model, firstly in terms of access to the university and secondly, and more importantly in current writings, access to success in the university (Scott 2014). The latter has become known as 'epistemological access' (Morrow 2007; Muller 2014). 
The concept of epistemological access is seen by many in the academic development field as a strongly sense making and appropriate lead theory to underpin student learning in foundation (Shay, Wolff \& Clarence 2016; Bozalek, Garraway \& McKenna 2011). This is partly because it calls on teaching staff to make clear to students the principles, values and ways of doing within their subjects and fields so that students may be more able to access these fields. Support for such an approach is reflected in FP policy (Department of Higher Education and Training 2012):

Foundation provision is the offering of modules, courses or other curricular elements that are intended to equip underprepared students with academic foundations that will enable them to successfully complete a university qualification that has been approved by the Minister of Higher Education and Training. Foundation provision focuses particularly on basic concepts, content and learning approaches that foster advanced learning.

Epistemological access (at least in the in the minds of academic developers) is currently the dominant or hegemonic theorisation for teaching and learning on foundation. To describe epistemological access as a theory or concept is perhaps misleading. The term as originally coined by Morrow (2007) was used to highlight the need for students, not just to gain physical access to university, but also access to their fields of study. However, what counts as epistemology in different knowledge fields is underpinned by Bernstein's theorisations of knowledge structures and Muller and Young's (2019) conceptualisation of 'powerful knowledge'.

The structure of the paper from here on is to firstly report on some of the more dominant attempts at theorisation of foundation teaching and learning, drawn from selected and significant recent publications. These predominantly realist approaches are outlined briefly below, and discussed and critiqued in more detail in the body of the article. Secondly, the article addresses some more recent and inventive approaches which are only recently emerging in the literature (for example in this volume).

Epistemological access, it can be argued, is a close companion to access to discourse theories (Gee 1996) of academic literacy. Furthermore, epistemological access underpins many of the realist theories as applied to HE. legitimation code theory (Maton 2014), for example, as a development of 
Bernstein's knowledge theories, highlights the pre-existence of disciplinary knowledge fields, as well as ways of knowing about these, that are independent of the learner.

Likewise, in social realism approaches, there are causal powers (in structures and cultures) which condition (through they do not determine) what actors can do in the world (Carter \& New 2004). In activity theory there is an understanding that historically developed systems pre-exist students' encounters with them. As with social realism, students may act to alter these systems through their agency, but generally within sets of pre-existing constraints. In constructivist approaches, at least those reported on in this article, the focus is often on active, group learning aimed at linking students prior knowledge to that of disciplines, thus helping them to co-construct their new understandings (Krige \& Bezuidenhout 2015).

But there is an emergent shift in thinking about guiding theories that are critical of and go beyond social realism, including EA and related theorisations. Some scholars have begun to challenge the dominance of knowledge fields without giving space to affect or the diverse ideas, concerns and knowledge that students bring with them, for example, Leibowitz (2017) and Zipin, Fataar and Brennan (2015). These authors question the very basis of claims that EA is a socially just initiative. For example, Zipin et al. (2015) argue that even the so-called powerful knowledge of disciplines, accrued over time, is always at some point socially constructed. Accordingly, knowledge, including scientific knowledge, may reflect the interests of particular groups, often to the detriment of other knowledge which may have worth. Added to this is the growing call for a re-visioning of university curricula from students themselves, often under the mantra of decolonisation and transformation, which again challenges the idea of whose powerful knowledge is being represented within the university classroom. Is, for example, knowledge simply an economic asset to support business development or a means to support social justice in society? As Zipin, Fataar and Brennan (2015) suggest:

Social realist arguments to centre curriculum on 'powerful knowledge' as policy makers (mis)read this to address 'education needed for the global knowledge economy' .... Yet we find that SR arguments shunt aside important ways of thinking about knowledge, power and curriculum that matter for socially just educational work (Zipin, Fataar \& Brennan 2015: 10). 


\section{Section 1: Current and Predominant Theorisations of Foundation}

In order to illustrate the current theorisations of FP/ECP teaching and learning a selection of sources published prior to mid-2019 (when this article was written) which illustrate the state of play of teaching in foundation are called upon here. For this first section, articles selected were, firstly, in volumes dedicated specifically to foundation teaching and thus more likely to depict the situation in FP/ECP teaching and learning. In addition, there was a significant and recent application of legitimation code theory to FP emanating from Rhodes University which is also covered here:

Ellery, K 2017. Conceptualising Knowledge for Access in the Sciences: Academic Development from a Social Realist Perspective. Higher Education 74, 5: 915 - 931.

Shay, S., K. Wolff \& J. Clarence 2016. New Generation Extended Curriculum:

The Flexible Degree Proposal. DOI: 10.13140/RG.2.1.3135.5767.

Pretoria: Department of Higher Education.

Young, G. 2015. South African Journal of Higher Education. (Special Foundation Edition) 29, 1.

Dhunpath, R. \& R. Vithal. 2014. Alternative Access to Higher Education:

Underprepared Students or Underprepared Institutions? Cape Town: Pearson.

Bozalek, V., J. Garraway \& S. McKenna 2011. Case Studies of Epistemological Access in Foundation/ Extended Curriculum Studies in South Africa. Higher Education Learning and Teaching Association of South Africa. Available at: http://heltasa.org.za/foundation/

Hutchings, C. \& J. Garraway 2010. Beyond the University Gates: Provision of Extended Curriculum Programmes in South Africa. Proceedings of the January 2009 Rhodes University Foundation Seminar hosted by Professor Chrissie Boughey. Higher Education Learning and Teaching Association of South Africa. Available at: http://heltasa.org.za/foundation/

\section{Epistemological Access}

One of the main thrusts in HE to achieve parity of outcomes for students from previously disadvantaged backgrounds is teaching for epistemological access 
i.e. access to the ways of doing and thinking at the university in their particular fields, as opposed to simply physical access (Morrow 2007) so that students are able to operate more confidently and independently. In Shay, Wolff and Clarence's (2016) research, epistemological access is clearly the theoretical underpinning of foundation undergraduate teaching and so also, by default, foundation teaching and learning (for example, see reference to 'epistemic transitions', P. ii). This position is also accentuated in the McKenna chapter in Dhunpath and Vithal's collected volume 'Alternative Access to Higher Education' (2014: 51):

Foundation provision is frequently reduced to remedial attempts to teach generic skills rather than calling on the kinds of teaching and learning approaches which make the university's way of constructing knowledge accessible to all students ... The chapter ends with a plea for foundation work to be undertaken with the explicit agenda of providing access to the discipline-specific ways of knowing found in the university.

Mckenna's arguments are further elucidated in later chapters in the same volume, for example Kioko, Barnley and Jayani (2014) description of Foundation Science's underpinning theorisations.

The concept of epistemological access is rooted in students being schooled in what is understood in some schools of thought as the 'powerful knowledge' of university disciplines (Young 2008). Teaching for epistemological access focuses on elucidating the key underpinning concepts/theories of a discipline which are generalizable across different contexts. For example, in history teaching the lecturer may use a local historical example as a case to illustrate a principle, but would then subsequently abstract the underlying theory principle. Student learning is focussed on learning underlying principles. It is thus not limited to the context in which knowledge has been learnt but may be applicable to analyse any number of cases in the future across different contexts. This is what makes the knowledge powerful (Young 2008).

Muller and Young (2019) suggest that so long as there are willing and able experts to teach for epistemological access, any student, regardless of their background, has the potential to acquire the powerful knowledge of university disciplines. Such access is thus not predicated on prior privileged schooling 
and upbringing, supporting Muller and Young's (2019) claim that teaching for EA in turn supports a social justice agenda within HE.

Muller and Young (2019) refer to the individual facts, concepts and methods which together make up a discipline; to be adept in any discipline students would need to know these propositions. But propositional knowledge is insufficient on its own if students are to gain access to the knowledge of the discipline, they also need to know how these propositions hang together into a comprehensible whole, what Muller refers to as 'knowing how' within a discipline. This is the level of knowing that enables students to explain events, produce legitimate text and even, possibly, use disciplinary knowledge in new ways. As Muller and Young (2019: 8) assert, it is knowledge of coherence rather than knowledge as a laundry list that matters, if students are to be given access. In a similar vein, Herbert et al (2011: 8) writing about foundation course design in Physics, suggest that:

Educators of Physics seldom succeed in students gaining the required deeper level of understanding that underlies key concepts and procedures ... (as) little attention is given to making explicit the links between concepts and the structure of knowledge in the discipline.

Shay, Wolff and Clarence (2016) further discuss different knowledge structures, drawing from the work of Bernstein (2000). Some fields are characterised by having a conceptual spine which carries through different years, and concepts are built sequentially, one after the other, with the early concepts enabling access to later ones. Such fields are typically in the so called 'hard' sciences (e.g. biology and economics). The humanities are more characterised by parallel languages rather than sequential concepts. Then there are many variations in between these two poles, but the point is that fields/disciplines have theories, concepts and bodies of knowledge and that it is the work of staff to induct students into these knowledges.

Such a forward looking approach is reflected in policy, as Shay, Wolff and Clarence (2016: 17 - 18) outline:

The (foundation) policy stipulates that the extra time must be used to provide additional curriculum time for foundational learning ... But the dominant logic is an attempt to strengthen the knowledge code with its emphasis on epistemic access through foundational provision. 


\section{Academic Literacies and Discourses}

The concepts of academic literacies and subject discourses are closely intertwined with epistemological access. Whereas epistemological access involves distinguishing between different forms of knowledge, each with its own peculiarities, academic literacy is a more inclusive term involving both producing appropriate text as well as taking on identities associated with the different forms of knowledge.

For Boughey (2010), literacy is a multiple rather than unitary phenomenon, and that it is more than the ability to read and write (this is also the position put forward by other academic literacy academics, for example Gee and Lea and Street below). She identifies multiple academic literacies, and these literacies are related to disciplinary difference. Academic literacy is much concerned as a counterpoint and challenge to the idea of 'deficit' in students and how this can be best approached through teaching students general English language skills and generic skills. Through mobilising the idea that academic literacies are not natural but culturally produced discourses that can only be acquired through direct teaching. McKenna suggests that:

if we become increasingly aware of how literacy practices are socially constructed and far from common sense, we can begin to make them more accessible to our students (McKenna 2010: 14).

A similar argument is raised in epistemological access approaches in that access is generally forward looking to what needs to be learnt at university rather than backward looking to what students do not know or cannot do coming from school.

Much of the academic literacy writings draw on the work of James Gee and 'Discourse'. Gee distinguishes between the capitalised Discourse, referring to fields of knowledge, and discourse with a small d, referring to a stretch of text. For Gee (1996: 143 - 146), within Discourse, there are different social identities in the world, each characterised by, for example, different values and ways of speaking and more generally behaving, which are known as discourses. In a similar light, different disciplines have different ways of doing, knowing and being which are not natural but need to be overtly learnt. In essence the student is taking on a new identity or multiple identities according to what it is they are engaged in. Again, as Herbert et al. (2011: 9), writing about access to Physics in the foundation classroom, outline: 
Discourse refers to the way in which a discipline represents itself - not just in words but in graphs, symbols and how its artefacts are used as well as the value commitments that underlie these representations ... and which place a greater emphasis on learning as participation and identity development

On first reading there seems to be a sense that students simply need to learn the 'rules of the game' and so become academically literate. But academic literacy is much more than just understanding a field, it is also, according to the authors in the foundation texts, about producing legitimate text within that field. Students, then, as producers of text, may have the opportunity to generate new ideas within the subject so the possibility is there for some form of change to existing knowledge.

If we discuss academic literacy at a purely functional level, then we expose ourselves to a totally assimilationist position whereby students are required only to conform to the practices of the disciplinary tribe. Failure to take a critical stance in a reflection on academic literacy 'can lead to higher education students becoming "reproducers of knowledge" engaged in "knowledge telling discourse" rather than "knowledge producers" engaged in "knowledge generating discourse" (McKenna 2010: 14).

However, for some authors academic literacy focuses not so much on discourse models but rather on more generic language skills deemed necessary to work with university texts:

... since the majority of students enrolled on this programme are second language English speakers the language and study skills modules included in the curriculum address a well recognised barrier to learning that most of these students are facing (Potgieter et al. 2015: 111)

... note taking and academic literacy in English and Afrikaans (including listening, speaking, reading and writing) (Krige \& Bezuidenhout 2015: 139).

The underlying reason for adopting the above approaches may be similar to 
those suggested earlier in an attempt to understand limited uptake of EA pedagogies. Of note, also, is that a theoretical approach, academic literacy, has been reworked to support a more common sense approach to teaching, a point also raised by Boughey 2014).

Epistemological access and academic literacy are dominant theorisations of knowledge within the university as evidenced in the literature reviewed. They are essentially realist in the sense that there is knowledge that exists before people encounter and work with it (Maxwell 2011). However, the authors here are wary of equating academic literacy directly to the concept of epistemological access. Lea and Street (2006) pose two related models for AL. The enculturation model, in which students are schooled in their disciplines, comes close to what is understood as EA. The second model, which also includes enculturation, involves the development of students' identity and voice. There is much more possibility of variance here as students are involved with 'meaning making, and identity that are implicit in the use of literacy practices within specific institutional settings' (Lea \& Street 2006: 370).

The following theorisations of teaching and learning, drawn from the selected literature support the epistemic access discourse, and on some occasions even challenge it.

\section{Legitimation Code Theory (LCT)}

LCT has not had much coverage in articles theorizing foundation provisions. However, at the Higher Education Close Up Conference summary panel at Lancaster in 2016 the paper presented by Karen Ellery (2017) on using LCT in FP was highlighted as an innovative approach, and is thus included here. In short LCT understands the social world as consisting of relatively autonomous fields each with their own favored knowledge resources and practices (Maton 2014). LCT draws heavily on the work of Basil Bernstein.

Bernstein's concern during his lifetime was with pedagogic democracy, in other words the equal access to pedagogic knowledge for all social groups (Bernstein 2000: Introduction). Bernstein coined the term 'classification' for disciplinary knowledge which referred to its distinctiveness and boundaried nature, which may be strong or weak. Some more established university disciplines - for example Natural Sciences, Psychology, Sociology and History - tend to be more strongly boundaried than newer subjects like film or gender studies. This was referred to as having a strong or distinct 
grammar versus a weaker grammar which is less well formed and more porous to new ideas (Bernstein 2000: 28). He further went on to classify knowledge fields according to their hierarchal or more parallel knowledge structures, as already expressed. What matters for learning, according to Bernstein (2000: 17), is that students are both able to recognise the distinctiveness of the discipline they are studying ('recognition rule') and also that they are able to mobilise this understanding in text production ('realisation rule').

Although Morrow does not refer to Bernstein in his work on epistemological access, both writers use the term 'grammars' in a similar fashion to denote distinctiveness. Later writers in the Bernsteinian tradition such as Shay, Clarence and Wolff (2016) and Muller (2014) draw out this connection further.

Maton (2014) suggests that although Bernstein's ideas gained traction in the sociology of education they were never fully operationalized at the level of pedagogy. LCT is an attempt to do this. LCT is concerned with identifying what counts in the social world both in terms of the required knowledge and its underlying principles but also the extent to which a particular way of knowing, or knower code, has effect. Codes refer to the underlying principles of what counts as legitimate knowledge, practice and achievement in a disciplinary field. They are enacted through socially agreed upon criteria that can be used to examine, for example, student text, to assess whether it is legitimate or not.

Where lecturers draw legitimation from, what principles they are following and what criteria they are using, has real impact on what they actually do in practice - in designing the curriculum, how they teach and how they assess, for example. Yet these codes are often tacit. Consequently, if students are not privy to these codes, access to knowledge and practice epistemological access - may be severely constrained. As Ellery (2017: 83) explains:

Code theory is premised on the idea that power and control manifest themselves through the structural and interactional aspects of practices, and therefore have the capacity to include or exclude. Analysing educational practices using code theory enables characterisation of the practices, highlights their underpinning principles (i.e. what is being legitimated), and allows for their effects to be considered. 
Furthermore, lecturers themselves are not always aware of the principles and criteria underpinning their own disciplines. Maton (2014) suggests that a systematic, LCT guided analysis of disciplinary knowledge is then also important for responsiveness and change in practice (Maton 2014). In Ellery's (2017) work she takes up this challenge as well as that of Bernstein's 'pedagogic democracy'. The author constructively suggests that pedagogies which help students to both recognise the characteristics of legitimate texts as well as how to produce such text are significant enablers toward successful outcomes for FP students.

\section{Archer's Social Realism}

Social realist approaches, as with LCT, acknowledge that pre-existing structures and ways of thinking have effect on current social practices. Social realist research follows a so-called 'stratified ontology'. By this is meant that what we observe happening around us are effects of deeper driving forces that are in part causative of empirical events (Carter \& New 2004). In Margaret Archer's model, these causative factors of changes in society can be ascribed to the separate but related social realms of structure, culture and agency, even though these may also be evident in observed social practices. Boughey (2014), for example, analyses academic development through the lens of these divisions in the real strata. Furthermore, processes of change are relational (Archer 1995) in that usually it is not just one of these elements which promotes change but an interaction between them. For example, structures in society (such as rules, policies etc.) may provide an enabling space and/or political force for a person to implement changes in their field (for example, in a university programme). Structural and cultural forces are 'real' in that they influence though do not determine what actors in society may do:

The social contexts which people inhabit ... provide people with 'directional guidance' in terms of appropriate beliefs and courses of action .... People as agents and actors are influenced, though not determined, by their structural situations (Carter \& New 2004: 6).

However, analytically, the researcher examines the domains of structure, culture and agency (SCA) as separate entities at one level as each has properties which can influence one or other of the domains. For example, an academic's 
drive to study a postgraduate teaching qualification in HE might largely emerge from their individual and persistent desire of "wanting to be a good teacher' but this would be enabled or constrained by the domains of structure and culture at the university, where the teacher may be encouraged to do such a qualification for probation purposes or may be constrained from doing so by heavy teaching loads.

SCA is thus also a realist framework in that it understands that there are social realities in the world that can in part determine or condition the possibilities for social change. Such social realities can be seen as independent of the society in which they play out; they precede what happens in society. Thus each of structure, culture and agency are understood as being real. Their 'realness' manifests itself in their having properties (emergent properties) which can influence the direction society takes. For example, Eybers (2015: 81) writing from a critical realist perspective on academic literacy facilitation in foundation takes a strong stance on disciplinarity, which has some resonance with epistemological access approaches:

It (academic literacy) should aim to facilitate learning practices which further student awareness of the values and associated practices of the particular discipline.

All along there is the influence of agents on the social system. Agents do inherit cultural and structural constraints and enablements from society and may accept or refuse them, if they are in fact aware of them.

These real properties may be changeable over time in particular when shifts emerge in society. This can, for example, be seen in the realness of university policy which can affect what people can and cannot do, or even promote resistance which can result in, ultimately, policy changes. The realm of ideas (culture) can also be seen in this way. For example, the culture of the interlinked ideas of student engagement, student centred teaching and promoting greater student autonomy in their learning may influence how staff perceive they ought to be teaching, and even promote critique and resistance to these ideas so that new realities may emerge. As Eybers (2015: 88) suggests:

... they (realist theories) afford greater causal efficacy to agency ... agency is critically embedded in a model whereby structures and 
cultures such as those of academic disciplines and student homes are seen to be in constant interplay in pedagogic environments.

Such a position of possible change, even though there needs to be homage paid to the nature of disciplines, is further suggested in Ellery and Baxen's (2015: 104) article on Science Foundation:

... while pedagogy may still assume in part an assimilationist stance it recognises individual projects and creates the space for their articulation and expression and seeks to enable transformation not reproduction.

\section{Activity Theory}

Activity theory, derived from an expansion of Vygotsky's mediated learning model, is also evident in the literature on foundation studies, but only in two articles. In activity, rather than focusing on what sorts of psychological/cultural tools students use or need in order to be 'mediated' in their learning, the whole system of learning is examined. For example, one may choose to examine the system of the classroom with its rules, culture hierarchy and other interested parties such as parents and administrators. Much interest is paid to the object which is understood as a relatively shifting focus of the activity system. The object is often described as the raw material which the whole activity system attempts to clarify (Sannino \& Engeström 2017).

Activity is primarily a way of understanding organisational difficulty and change which has more recently been used in classroom learning. Vygotskian principles such as double stimulation, the existence of major contradictions in any social system and development arising from their identification and resolution, drawn from dialectical materialism (Virkkunen $\&$ Newnham 2013) and the origination of a zone of proximal development are all core principles for learning and change. However, in activity, the ZPD refers more to the developmental space between the current activity system and, through analysing difficulties, the new more advanced emerging system. What eventually transpires is initially unknown, so referred to as 'possibility knowledge' by Sannino and Engeström (2017).

Researchers using activity theory in researching foundation tend to limit themselves more on the activity system of the classroom/university and 
how implementing changes in different components can affect the whole system and in particular changes in the object. Kizito (2015: 219), writing about the analysis of Science Foundation suggest the usefulness of activity as a theoretical framework:

... a conceptual map could be constructed of the main components within a programme and how they interaction ... accommodating all the participants in the project and their contributions .... Understanding the tensions and contradictions among the components of the system could shed light on what motivates particular actions and what affects the evolution of the system ....

Activity takes for granted that there are real effects in society, such as rules, cultures and tools, as well as deeply embedded historical trends, and that these influence the object of learning but do not predetermine it. However, activity is not yet used to its full potential in the (few) studies examined. Activity has a strong tradition of dialectics, for example between students' prior/experiential knowledge and course content. The role of the educator is to understand and attempt to work across this dialectic, which is necessarily different for different disciplines (Edwards 2017). Furthermore, the activity system, for example the classroom and it practices is itself seen as changeable as students introduce new ideas and practices; it is not just the student who potentially develops (Engeström \& Sannino 2011). Activity theory highlights the object-motive in learning and development, that different students and staff attach different meanings to tasks and that this may constrain engagement (Edwards 2017). An object-motive focus highlights the importance of student agency in learning, an issue explored as well in Archer's social realism theorisations.

\section{Active Learning and Co-construction of Knowledge}

Foundation traditionally promotes active, group learning methods with the smaller student groups typical of foundation classrooms. In a similar vein to activity, active learning approaches frequently draw on the work of Vygotsky, but is also, as suggested here, often undertheorized. For example, Potgieter et al. (2015: 111) writing on Science Foundation make the following practical suggestion which is not further explored theoretically: 
Teaching and learning takes place in smaller groups. This allows for individual attention and gives ample opportunity for questions and discussion.

Active learning often involves students in the construction of knowledge through group activities. Writers in the active/group work arena aim to use these approaches to help students access the discourses of their disciplines. This is in contrast to more instructional 'chalk-and-talk' pedagogies. Krige and Bezuidenhout (2015: 139) refer to these constructivist principles in Foundation Communications Science ('Objective' here refers to a focus on what students need to learn):

The co-operative teaching and learning approach is situated between the continua of collective and objective, calling for collective efforts by group members to work together in examining existing knowledge.

Writers refer to constructivist approaches sometimes with specific reference to Vygotsky's theorisation of mediated learning, for example within the zone of proximal development. Krige and Bezuidenhout (2015: 139) outline their pedagogic approach in Foundation Communication studies thus:

(Vygotsky's) theories and their principles form the premise for learning facilitation .... The principles include: using the student's experience as the foundation for learning; constructing knowledge in social contexts, allowing active student participation in the interpretation of information, and engaging with knowledgeable others to enable meaning-making through integration and application of information.

McGhie and Du Preez (2015: 167) writing on foundation provision in Management Studies expands on these constructivist principles to include learning principles from social learning, as well as the creation of more enabling learning environments:

A theory of social learning is based on ... learning as belonging, learning as becoming, learning as experience and learning as doing ... Four (additional) principles are directly applicable to this project ... 
learning is developmental ... learning (occurs) through social interaction ... a positive emotional environment strengthens learning ... the total environment influences learning.

Active learning undoubtedly has value in inducting students into university, Tinto (2012) makes strong claims that such approaches promote learning retention and success in particular in socially disadvantaged students in the USA. Although some authors (for example Krige \& Bezuidenhout and McGhie \& Du Preez above) invoke constructivist and other learning principles to background their pedagogical approaches, more could perhaps be done given the extent of active learning approaches in foundation.

As things stand, engagement and reference to constructivism, drawing on Vygotsky's work remain quite theoretically underdeveloped. For example, there is little or no reference to the principle of dialectics in how students respond differently in navigating between their own desires and backgrounds and the exigencies of the new field of Higher Education (Edwards 2017).

Although social realist accounts of knowledge and pedagogy are undoubtedly useful in guiding staff in what they teach and how this can be best undertaken in the classroom, reservations have been raised about epistemological access to the so-called 'powerful knowledge' of disciplines. Leibowitz (2017) argues that realist approaches separate out knowledge from how it is taught, suggesting that, particularly in the light of recent calls for curriculum decolonisation, different knowledges need to be acknowledged as having value, and so used to add to and even interrogate the curriculum and its delivery. Zipin, Fataar and Brennan (2015) argue further that 'powerful knowledge' is often knowledge created and circulated within elite, groups rather than an objective, universal source of truth. It thus, they argue, may represent a particular version of knowledge rather than a value-free universal.

Despite these assertions, realist-related accounts of knowledge and related pedagogies involving concepts such as powerful knowledge and epistemological access may be something of a theoretical lock in. 'Lock-ins' is a concept borrowed from technology innovation studies, and refers to decisions taken at some early stage of development which may serve to cut out other, more heterogeneous ideas (Rip 2000) (one such example in technology may be the lock in in the past to internal combustion rather than electric vehicles). Leibowitz and Bozalek (2015: 13), writing in the SAJHE special edition on Foundation Provision Research, propose, quoting from Crain 
Soudien's Higher Education Teaching and Learning Association in Southern Africa's (HELTASA's) keynote presentation (2012), that there should be an approach to access that:

... is prepared to engage with the whole spectrum of knowledges and understandings that live on the South African social and cultural landscape, those that are described as Western, African, modern, traditional, 'powerful', 'useful' and so on, and, fundamentally, the whole spectrum of people that are the living bearers of these knowledges.

Soudien's comments raise possibilities of alternative theorisations, in particular under the thematic of social justice. The next section takes forward the notion of social justice in relation to FP in relation to affirming difference as normative rather than seeing it as abject, and something to be addressed which is generally the position of FP programmes. .

\section{Section 2: New directions in Foundational Provision Studies}

This section looks at two different approaches which have been used more recently to contribute to the debates on foundation provision or extended curriculum programmes - that of Universal Design for Learning (UDL) and critical posthumanism or feminist new materialism.

\section{Universal Design for Learning}

In a special issue on Foundation Provision in the South African Journal of Higher Education, Leibowitz and Bozalek (2015) considered how social justice approaches such as the Universal Design for Learning (UDL) could provide an expansive vision of equity in $\mathrm{HE}$, as they embrace differences which they regard as the norm rather than the exception (O'Brien 2005). The UDL sees dis/ability on a continuum and proposes that higher education institutions (HEIs) creatively develop an inclusive curriculum, providing differential opportunities based on students' learning needs. This would mean that instead of relegating certain students to a Foundation Programme, difference is regarded as the norm rather than the exception, and all students are accommodating in so-called 'mainstream' classes, where emphasis is placed 
the sorts of social and curriculum arrangements needed to optimally enhance and expand capabilities and learning potential. Here the focus is on the required social arrangements which can lead to curriculum renewal and change, in order to develop a more inclusive approach to learning. The UDL thus goes some way towards establishing the importance of materiality in normalizing difference by making disability a condition of the curriculum rather than the human.

Approaches discussed below take the idea of difference as normative further, including among other considerations, the importance of matter and materiality in their views of social justice.

\section{Critical Posthumanism, Non-representational Theory and Feminist New Materialism for Reconfiguring ECPs}

How do critical posthumanism, non-representational theory and feminist new materialism differ from prior theoretical approaches to extended curriculum programme teaching and learning? Firstly, these theoretical approaches are based on process philosophies, which lead them to be interested in relation, event, and experimenting with process, rather than a fixation on the end product, the predefined outcome, the valorisable object or artefact (Ehret \& Leander 2019; Massumi 2015; Murphie 2018). These approaches also focus on transforming potential and a focus on the new - what inventive and experimental approaches can bring that is new to the process of learning.

Secondly, these approaches are non-representational - which means that they contest the fact that the world is made up of individual entities which precede relationships and have inherent characteristics, prior to their representations. That is, they do not believe in the separation or distinction between representations and independent entities. Rather, the world is seen as material-discursive - of the inseparability of meaning and matter (Barad 2007).

Thirdly, all these approaches pay scholarly attentiveness to ethics and ontology as well as epistemology which they see as inseparable - Karen Barad (2007), an eminent feminist new materialist and posthumanist, refers to this entanglement as ethico-onto-epistemology. In other words, these approaches make ontological and ethical claims, (these approaches are also referred to as the ontological turn) in addition to epistemological ones, the latter being the focus of all previously discussed theories in this paper. 
Fourthly, these theories are built on the presumption that matter is important and that it is indeterminate. This would mean that entities 'do not have determinate boundaries and properties and words do not have inherently determinate meanings' (de Freitas \& Sinclair 2014: 44). Agency is spread across entities - whether they be human or non-human and is seen as an enactment, rather than residing in intentional human beings.

Fifthly, these approaches are also all predicated on a relational ontology. This means that entities come into being through relationships rather than preceding them. In an ECP programme, it would mean that there are no self-contained entities, or stabilised identities, but that all is entangled - human, non-human and more-than-human. There is also a recognition that the material world such as texts and humans are iterative and mutually constitute each other - rather than being unidirectional. For example, from a critical posthumanist, non-representational theoretical and feminist new materialist position, reading and writing practices involve close, respectful, inventive and responsive relationships of careful attention to details, doing justice to texts. Texts are themselves seen as agentic and as changing humans and vice versa - Barad (2007: x) for example, notes that 'writing is not a unidirectional practice of creation that flows from author to page, but rather the practice of writing is an iterative and mutually constitutive working out, and reworking of 'book' and 'author'.' Here, the processual qualities and the focus on activity and on 'becoming' rather than being, are important. Subjects and objects, including 'knowledges' are not pre-constituted, but are in a state of flux, come into being through relationships and are situational. From these perspectives, mediation, as is used in activity theory, is not necessary as relationships pre-exist entities and entities come into being through relations. Mediation assumes that preexisting entities such as humans need access to concepts through a process of mediation rather than coming into being through relationships.

Critical posthumanism, non-representational theory and feminist new materialism are transgressive approaches to scholarly practice in that they emphasise the undetermined potentials in the immanent capacities of learning processes. For ECP and other learning programmes, this means that it is difficult to predict how learning will happen, and that it is the events themselves which are significant, rather than the individual human and nonhuman actors such as the commodification of the pre-set curriculum. Practices such as dialogical feedback which happens between learners and teachers which in themselves are processual and response-able would be coherent with 
critical posthumanism, non-representational theory and feminist new materialism. Such practices would be seen to extend both learners and teachers, as well as the texts themselves in terms of being co-constitutive and rendering each other capable (Despret 2016; Haraway 2016).

Critical posthumanism, non-representational theory and feminist new materialist approaches are also transdisciplinary - as Åsberg and Braidotti (2018: 1), put it 'where science needs to meet cultural knowledge on values, sense-making, politics and purpose, and where the humanities and social sciences meets postnatural nature' - thus emphasising the transversal. For ECPs from these perspectives then, it would make better sense to organise these as transdisciplinary programmes in which the complexity natureculture is entangled, rather than sticking to narrow domains, and leaving nature to science and culture to the humanities. An example of natureculture crosspollination is the field of biodiversity which encompasses the natural sciences, humanities, law, economic and management sciences. In the face of the current crisis of the anthropocene, these would be important steps to take in acknowledgeing that '[o]ntologically, the world we inhabit is not bifurcated in this simplistic manner. Consequently, we need ethical research practices and epistemologies that dare step out of disciplinary comfort zones' (Åsberg \& Braidotti 2018: 2).

Critical posthumanism, non-representational theory and feminist new materialism have enabled ECP practitioners such as Delphi Carstens and Nike Romano in this volume, to move beyond representational logics which assume the centrality of the human, and see the human and the discursive as separate from matter (Ehret \& Leander 2019), to a dis-identification with Man as individual and as Anthropos to 'becoming-indigenous/other (racialization) and becoming earth (ecologization)' (Braidotti 2018: 10). Carstens and Romano show how in the extended curriculum programme, critical posthumanism, nonrepresentational theory and feminist new materialism 'can be put to the collective task of constructing new subjects of knowledge, through immanent assemblages or transversal alliances between multiple actors' (Braidotti 2018: 6). Furthermore, the papers written by Carstens and Romano in this volume illustrate how the 'ontological turn', as critical posthumanism, nonrepresentational theory and feminist new materialism is sometimes referred to, encompasses attentiveness towards immanent ethico-politics, which matter, and to which we are response-able and accountable (Barad 2007; Braidotti 2018; Haraway 2016). This implies, as Betty St. Pierre (2013: 655) notes, 'if 
we see ourselves as always already entangled with, not separate from or superior to matter, our responsibility to being becomes more urgent and constant'.

As Braidotti (2018: 1) reminds us, 'the posthuman knowing subject has to be understood as a relational embodied and embedded, affective and accountable entity and not only as a transcendental consciousness', which implies both a mindbody and a natureculture continuum and a transdisciplinary field of scholarship. In addition, we are always 'subjects-in-process', becoming-with human and non-human others in 'perpetual motion' (Braidotti 2018: 6).

\section{Conclusion}

Foundation provision is intended to both help students transition from school/work into first year as well as to navigate disciplinary discourses and develop a critical societal awareness. Such provision is seen as a vital initiative to improve quality and equity of outcomes in higher education. So much so that recent funding letters to universities have requested that they increase their foundation student numbers from the current $14 \%$ to $20 \%$ of the first year intake. Current debates in the literature on foundation teaching centre largely around social realist theorisations. These have been incredibly useful in focusing attention on barriers to students' access to knowledge, and to promoting more active learning approaches. Nevertheless, there is also a need to open up spaces for less normative, fresh and potentially disruptive social theories that can enrich our understanding of foundation provision. The past few years have seen an explosion of (relatively) fresh theorisations of teaching, learning and curriculum. For example the work of posthumanist and feminist new materialist writers including Braidotti, Barad, Haraway, as well as Deleuze and Guatarri, Massumi and Ettinger have brought about new contestations and disruptions to conventional pedagogical and curriculum practices. Thus the purpose of this article is to encourage the emergence of and discussion of theorisations of teaching and learning in foundation provision, including more recent ones, which can expand on and influence our understandings. As Ashwin (2017) reminds us, research can simplify and elucidate what is involved in best practices of learning to teach. Furthermore, given the complexity and challenges in FP practices, we need as many such simplifications as possible. 


\section{References}

Archer, M. 1995. Realist Social Theory: The Morphogenetic Approach. Cambridge: Cambridge University Press. https://doi.org/10.1017/CBO9780511557675

Åsberg, C. \& R. Braidotti 2018. Feminist Posthumanities: An Introduction. In Åsberg, C. \& R. Braidotti. (eds.): A Feminist Companion to the Posthumanities. Charn: Springer. https://doi.org/10.1007/978-3-31962140-1

Ashwin, P. 2017. PostScript on Theorising and Learning to Teach: Insights, Absences and Future Possibilities. In Leibowitz, B., V. Bozalek \& P. Kahn. (eds): Theorising Learning to Teach in Higher Education. London: Routledge.

Barad, K. 2007. Meeting the Universe Halfway: Quantum Physics and the Entanglement of Matter and Meaning. Durham \& London: Duke University Press. https://doi.org/10.1215/9780822388128

Bernstein, B. 2000. Pedagogy, Symbolic Control and Identity. Oxford: Rowan and Littlefield.

Boughey, C. 2010. Understanding Teaching and Learning at Foundation Level:

A 'Critical' Imperative? In Hutchings, C. \& J. Garraway (eds.): Beyond the University Gates: Provision of Extended Curriculum Programmes in South Africa. (Proceedings of the January 2009 Rhodes University Foundation Seminar hosted by Professor Chrissie Boughey.)

Boughey, C. 2014. The Significance of Culture, Structure and Agency in Supporting and Developing Student Learning in South Africa. In

Dhunpath, R. \& R. Vithal (eds.): Alternative Access to Higher Education.

Cape Town: Pearson.

Bozalek, V., J. Garraway \& S. Mckenna 2011. Case Studies of Epistemological Access in Foundation/ Extended Curriculum Studies in South Africa. Higher Education Learning and Teaching Association of South Africa. Available at: http://heltasa.org.za/foundation/

Braidotti, R. 2018. A Theoretical Framework for the Critical Posthumanities. Theory, Culture and Society 00: $1-31$.

https://doi.org/10.1177/0263276418771486

Broekhuizen, H., S. van der Berg \& H. Hofmeyr 2016. Higher Education Access and Outcomes for the 2008 National Matric Cohort. Stellenbosch: Bureau for Economic Research. 
James Garraway \& Vivienne Bozalek

Carter, B. \& C. New 2004. Realist Social Theory and Empirical Research

Paper to be presented at ESA Social Theory Conference, Paris, September $15^{\text {th }}-17^{\text {th }} 2004$.

De Freitas, E. \& N. Sinclair 2014. Mathematics and the Body: Material Entanglements in the Classroom. New York: Cambridge University Press. https://doi.org/10.1017/CBO9781139600378

Department of Higher Education 2012. Foundation Provision in Ministerially Approved Programmes. Pretoria: Government Printers.

Despret, V. 2016. What would Animals Say if we Asked the Right Questions? Minneapolis: University of Minnesota Press.

Dhunpath, R. \& R. Vithal 2014. Alternative Access to Higher Education: Underprepared Students or Underprepared Institutions? Cape Town: Pearson.

Edwards, A. 2017. Cultural-historical Approaches to Teaching and Learning. In Leibowitz, B., V. Bozalek \& P. Kahn (eds.): Theorising Learning to Teach in Higher Education. London: Routledge.

Ehret, C. \& K.M. Leander 2019. Introduction. In Leander, K. \& C. Ehret (eds.): Affect in Literacy Learning and Teaching: Pedagogies, Politics and Coming to Know. London and New York: Routledge.

https://doi.org/10.4324/9781351256766-1

Ellery, K. 2017. Conceptualising Knowledge for Access in the Sciences:

Academic Development from a Social Realist Perspective. Higher Education 74, 5: 915 - 931.

https://doi.org/10.1007/s10734-016-0085-x

Ellery. K. \& J. Baxen 2015. 'I always knew I would go to university': A Social Realist Account of Student Agency. South African Journal of Higher Education 29, 1: 91 - 107. https://doi.org/10.20853/29-1-453

Eybers, O. 2015. From Mechanist to Critical Realist Interrogations of Academic Literacy in ECP. South African Journal of Higher Education 29, 1: 79 - 90. https://doi.org/10.20853/29-1-449

Gee, J. 1996. Social Linguistics and Literacies: Ideologies in Discourse. London: Taylor and Francis.

Haraway, D. 2016. Staying with the Trouble: Making Kin in the Chthulucene.

Durham and London: Duke University Press.

https://doi.org/10.1215/9780822373780

Herbert, M., H. Conana, T. Volkwyn \& D. Marshall 2011. Multiple Modes of Epistemological Access in Physics. In Bozalek, V., J. Garraway \& S. 
McKenna (eds.): Case Studies of Epistemological Access. Cape Town: HELTASA.

Kioko, J., S. Barnsley \& D. Jaganyi 2014. Science Access: An Appraisal of Graduation and Throughput Rates. In Dhunpath, R. \& R. Vithal (eds.): Alternative Access to Higher Education. Pinelands: Pearson.

Kizito, R. 2015. Structuring an Activity-based Framework for Evaluating a Science ECP. South African Journal of Higher Education 29, 1:211 - 237. Kloot, B., J. Case \& D. Marshall 2008. A Critical Review of the Educational Philosophies Underpinning Science and Engineering Foundation Programmes. South African Journal of Higher Education 22, 4: 799 - 816. https://doi.org/10.4314/sajhe.v22i4.25817

Krige, D. \& J. Bezuidenhout 2015. Philosophy and Role Reflection of Teaching Practices in the Communications ECP. South African Journal of Higher Education 29, 1: 132 - 149.

Lea, M. \& B. Street 2006. The Academic Literacies Model: Theory and Applications. Theory into Practice 45, 4: 368 - 377.

https://doi.org/10.1207/s15430421tip4504 11

Leibowitz, B. 2017. Cognitive Justice and the Higher Education Curriculum. Journal of Education 68: 93 - 112.

Leibowitz, B. \& V. Bozalek 2015. Foundation Provision - A Social Justice Perspective. South African Journal of Higher Education 29, 1: 8 - 25. https://doi.org/10.20853/29-1-447

Massumi, B. 2015. Politics of Affect. Cambridge: Polity.

Maton, K. 2014. Knowledge and Knowers: Towards a Realist Sociology of Education. London: Routledge.

https://doi.org/10.4324/9780203885734

Maxwell, J. 2011. A Realist Approach to Qualitative Research. London: Sage. McGhie, V. \& M. du Preez 2015. Addressing the Learning Needs of At Risk Students at UWC. South African Journal of Higher Education 29, 1: 164 -180 .

https://doi.org/10.20853/29-1-452

McKenna, S. 2010. Cracking the Code of Academic Literacy: An Ideological Perspective. In Hutchings, C. \& J. Garraway (eds.): Beyond the University Gates: Provision of Extended Curriculum Programmes in South Africa. (Proceedings of the January 2009 Rhodes University Foundation Seminar hosted by Professor Chrissie Boughey.) HELTASA Avaialble at: http://heltasa.org.za/foundation/ 
McKenna, S. 2014. The Context of Access and Foundation Provisioning in South Africa. In Dhunpath, R. \& R. Vithal (eds.): Alternative Access to Higher Education. Pinelands: Pearson.

Ministerial Statement on University Funding. 2017/18. Pretoria: Department of Higher Education.

Morrow, W. 2007. Learning to Teach in South Africa. Cape Town: HSRC Press.

Muller, J. 2014. Every Picture Tells a Story: Epistemological Access and Knowledge. Education as Change 18, 2: 255 - 269.

https://doi.org/10.1080/16823206.2014.932256

Muller. J \& M. Young 2019. Knowledge, Power and Powerful Knowledge

Revisited. The Curriculum Journal.

https://doi.org/10.1080/09585176.2019.1570292

Murphie, A. 2018. Fielding Affect: Some Propositions. Capacious: Journal for Emerging Affect Inquiry. Capacious 1, 3. http://capaciousjournal.com/ | DOI: https://doi.org/10.22387/CAP2018.21

O'Brien, R. 2005. Bodies in Revolt: Gender, Disability and a Workplace Ethic of Care. New York and London: Routledge.

Potgieter, M., A. Harding \& Q. Kritzinger 2015. Reflections of Science Students on their Experiences of an AD Programme. South African Journal of Higher Education 29, 1: 108 - 131.

https://doi.org/10.20853/29-1-446

Rip, A. 2000. Fashions, Lock-ins and the Heterogeneity of Knowledge Production. In Jacobs, M. \& T. Hellstrom (eds): The Future of Knowledge Production in the Academy. Buckingham: OUP.

Sannino, A. \& Y. Engeström 2017. Co-generation of Societally Impactful Knowledge in Change Laboratories. Management Learning 48, 1: 80 - 96. https://doi.org/10.1177/1350507616671285

Scott, I. 2014. Access, Success and Curriculum. In Dhunpath, R. \& R. Vithal (eds.): Alternative Access to Higher Education. Pinelands: Pearson.

Scott, I., N. Yeld \& J. Hendry 2007. A Case for Improving Teaching and Learning in South African Higher Education. Higher Education Monitor. Number 6. Pretoria: Council for Higher Education.

Shay, S., K. Wolff \& S. Clarence 2016. New Generation Extended Curriculum. The Flexible Degree Proposal. Pretoria: Department of Higher Education. DOI: $10.13140 \% 2 F R G .2 .1 .3135 .5767$

Soudien, C. 2012. Unpublished Keynote Presentation at the Higher Education 
Learning and Teaching Association of Southern Africa Conference. University of Stellenbosch, November 2012.

St. Pierre, E. 2013. The Posts Continue: Becoming. International Journal of

Qualitative Studies in Education 26, 6:646 - 657.

https://doi.org/10.1080/09518398.2013.788754

Tinto, V. 2012. Completing College. Chicago: University of Chicago Press.

Virkkunen, J. \& D. Newnham 2013. The Change Laboratory: A Tool for Collaborative Development of Work and Education. Rotterdam: Sense Publishers.

Young, M. 2008. Bringing Knowledge Back in: from Social Constructivism to Social Realism in the Sociology of Education. London: Routledge.

https://doi.org/10.4324/9780203073667

Zipin, L., A. Fataar \& M. Brennan 2015. Can Social Realism do Social Justice? Education as Change 19, 2: 9 - 36.

https://doi.org/10.1080/16823206.2015.1085610

James Garraway

Professional Education Research Unit (PERI)

Fundani Centre for Higher Education Cape Peninsula University of Technology garrawayj@cput.ac.za

Vivienne Bozalek Director of Teaching and Learning University of the Western Cape vbozalek@gmail.com 